\title{
Methodology of mastering academic writing competence in English within program of university training
}

\author{
T. N.Astafurova \\ Volgograd State University \\ VolSU \\ Volgograd, Russia \\ t.astafurova@volsu.ru
}

\author{
I. V.Skrynnikova \\ Volgograd State University \\ VolSU \\ Volgograd, Russia \\ i.skrynnikova@volsu.ru
}

\author{
N. A.Sytina \\ Volgograd State University \\ VolSU \\ Volgograd, Russia \\ n.sityna@volsu.ru
}

\begin{abstract}
The article analyzes the process of mastering academic writing competence in English (within the program of university training) as a basic component of the academic culture that enables integrating into international scientific environment. The authors clarify the learning content of the program, the technologies of mastering structural, compositional, lexical, grammatical and syntactic components of academic writing competence; strategies and peculiarities of post-writing and submitting an article to a journal. The paper is an attempt to present a multi-faceted model of teaching an introductory course of academic writing in English within the program of university training.
\end{abstract}

Keywords-academic writing, competence; structural, compositional, lexical, grammatical, syntactic aspects; technology; intercultural scientific communication, module.

\section{INTRODUCTION}

For many centuries, academic writing was distinguished by elitism and isolation from the basic language of the state, being a sign of educated people of noble origin, a source of scientific terminology for the European languages. Academic writing was also considered as an indicator of unsurpassed results in generating and transferring new knowledge, ideas and achievements in various spheres of life. Rapid scientific progress and the industrial revolution in England in the eighteenth century have turned English into the language of academic writing, which conventions and rules gradually began to penetrate into the languages of Europe, including the Russian language. Fast technological developments of Great Britain in the late nineteenth and early twentieth centuries made English the language of international communication, which, as the dominant one, was established in the academic writing of other world languages. Over time, the sign of elitism has transformed into an attribute of scientific discourse, i.e. organization, structure and verbalization of scientific knowledge, which reflected the specific features of academic activity and multilevel peculiarities of the language, the instrument of the cognitive exploration of the world.

Academic writing in English is currently being taught in various formats around the world. But until recently in Russia, academic writing was not a part of university curriculum and not even considered as a component of the professional and scientific competence of a researcher. However, modernization of higher education in Russia required active involvement of science in education, new knowledge production, characterized by interdisciplinary features, innovation and social demand. And if education is, to some extent, more conservative and transfers knowledge already established in a society, science is international and closely related to the development of research skills, critical and creative thinking, professional self-determination and selfeducation, reading and writing culture [1].

\section{STATING THE PROBLEM}

In Russian universities, unfortunately, not only students, but also teachers are hardly aware of a written academic text to be primary, with oral presentation being a secondary product. This can be explained by many decades of promoting the communicative approach to foreign language teaching, which mainly underestimated the grammatical approach and excluded teaching writing skills from the curriculum. And only these days, the Russian academic world is gradually coming to understand the special importance of writing culture, including academic one, for successful interaction in professional and international scientific environment. This is due to the strengthening of the research component in universities' educational performance and the ever-increasing demand to enhance publication activity of the faculty in 
international peer-reviewed journals indexed in Web of Science, Scopus and other international scientific databases.

The acquaintance with the peculiarities of the composition of a foreign-language scientific text and the modeling of its structure, identification of ethno-cultural specificity of academic interaction in the written form and overcoming discursive stereotypes are becoming the most significant areas of investigating intercultural scientific communication [2]. This explains special urgency of developing learner's competence of academic writing in English.

The purpose of this article is to present a complex study of learning content in the program of professional development "Fundamentals of foreign-language academic writing" that assumes developing learners' writing competence in English. Scientific novelty of the article is determined by understanding learners' competence in academic writing as a central component of their scientific speech culture that enables active integration into the international scientific community.

The culture of presenting scientific knowledge is focused traditionally on the effective performing cognitive, representative and communicative functions of the academic text. Therefore, teaching of academic writing culture involves developing the ability to understand, analyze and create academic texts of various professional spheres [3]. The specificity of mastering writing competence in English within the university in-training program is being analyzes, and the results of the study may find practical application in teaching undergraduate and postgraduate students a foreign language, taking into account genre peculiarities of the scientific style, its structural, compositional, lexical, grammatical and stylistic characteristics.

\section{A. COMPETENCE COMPONENTS \\ DEVELOPED IN ACADEMIC WRITING IN ENGLISH}

One of the parameters that may determine a successful academic career of a university lecturer is his / her academic writing competence, including that in English, which enables one to create "author's identity" of a researcher [4] in the international context, to verbalize critical expertise, "to innovate, to challenge and to re-create the discourse of the other ... of the academic community" [5].

Analysis of modern studies on the development of academic writing skills [6-16] has revealed that the results of the course in academic writing suggest that learners have to:

- know the basic principles of the nonlinear construction of scientific / academic text as an integrated system; the fundamental differences of scientific text from other genres of academic discourse; international norms and the requirements of a scientific text;

- be able to logically build the text and organize its elements; put forward and justify one's own hypothesis; formulate a thesis and construct a text from hypothesis to conclusion; critically evaluate, select, synthesize and use information from various sources; write logically coherent and syntactically cohesive text; express one's ideas in a clear and precise language [6].

This set of goals and tasks highlights the need for mastering general cultural, general professional and professional competencies in accordance with the Russian Federal State Educational Standard.

\section{General cultural competencies (GCs) include:}

GC-3 - being ready for self-development, self-realization, of creative and scientific potential;

GC-10 - mastering a foreign language at the level that enables one to receive and evaluate information from foreign sources for academic and professional activities.

\section{General professional competences (GPCs) include:}

GPC-1 - being ready to communicate in a foreign language in a written form for solving problems of academic and professional activities;

GPC-5 - mastering a foreign language at the level of professional communication.

\section{Professional competencies (PCs) include:}

PC-1 - the ability to generalize and critically evaluate the results obtained by domestic and foreign researchers, to identify prospective directions, to compile a research program;

PC-2 - the ability to substantiate the relevance, theoretical and practical significance of the selected topic of scientific research;

PC-4 - the ability to present the results of the study to the academic community in the form of an article or a report.

Success in teaching fundamentals of academic writing in English largely depends on a clearly verbalized learning objective. The objective is defined as professional development of learners due to comprehensive enhancing their knowledge of basic principles of a foreign academic text as an integrated system, its characteristic differences from the Russian one, acquisition of international norms and requirements for a research article, step-by-step study of compositional structure of scientific article format AIMRAD (Abstract, Introduction, Methods, Results and Discussion) [2].

\section{B. PROGRAM MODULES}

The original foreign language proficiency level as well as the needs of the learners predetermined two target groups (linguists and non-linguists). It resulted in two modules of the program "Fundamentals of academic writing in English", that focuses on the study of the structural, compositional, lexical, grammatical, functional and stylistic features of an academic text; the analysis of the categories affecting the correct scientific knowledge transfer in a foreign language:

English.

the first module for linguists is being taught in

the second module for non-linguists is being taught in Russian, providing lecturers of other disciplines with basic academic text structures in English. 
The first module of the program is intended for university teachers not acquainted with the fundamentals of academic writing in English, but having a sufficiently high level of foreign language competence. This module includes five sections, each accounting for 4 academic hours; the training lasts for 20 hours of classroom work and 52 hours of independent activities.

In the first section of the module, special attention is paid to:

- analysis of the strategies and techniques prior to writing scientific text in a foreign language (brainstorming, mental mapping, free writing, question-asking, etc.),

- general requirements for scientific work, types of academic texts, the specificity of the scientific style;

- most typical errors in written academic work, specificity of using sources;

- the peculiarities of structuring a scientific text in English.

The above-mentioned knowledge helps learners to integrate into the international scientific paradigm which significantly differs from the Russian one, and to obtain a consistent idea of how to write scientific articles in English in order to maximize the chance of being published in foreign journals indexed in international research databases.

The structural peculiarities of a foreign academic text are of equal importance in teaching learners. The peculiarities include:

- the structure of a scientific article; its main sections (introduction, review of theoretical background, selection and review of sources, citation, extension of the hypothesis);

- meta-communication signals of the main parts of the text, the progress of the study (experiment, statistics), conclusion, opinions and the perspective of the research;

- footnotes, charts, indication of the sources of funding the study and its participants;

- the wording of the article's title and annotation (abstract).

Meta-communication signals used for structuring a scientific text and verbalizing the intention of the researcher are acquired through the analysis of authentic scientific texts of different genres, their performance and functions. Metacommunication signals of a scientific text are organized according to intentional categories and may be regarded as a sort of pillars for a more accurate expression of researcher's intentions.

The lexical-grammatical section of the module focuses on developing learners' foreign language competence:

- in choosing adequate scientific vocabulary, terminology, expressions and clichés of academic English avoiding lexemes and phrases not typical for academic texts, 'strong' verbs to formulate goals (to reveal, to establish, to explore, to investigate, to assess) and to explain the concepts of the research;
- in correct employment of tenses and voices, prepositions and articles, non-finite forms of the verb (infinitive, gerund, participle) and grammatical constructions with them;

- in avoiding repetition, paraphrase, distinguishing between British and American academic English.

Exercises developing these skills focus on the analysis of definitions of terms and selection of the most accurate ones; the identification of informal lexical items and their replacement by academic synonyms; correction of spelling in scientific terms; replacement of polysemantic verbs by more exact units belonging to the scientific style; the correct employment of structures with the infinitive, participle, gerund, etc.

\section{For example:}

1) Put a tick next to the following sentences which are formal and therefore suitable an academic writing. Tick the sentence if it is too informal to be appropriate for academic writing. Explain why.

1. But there are a lot of things that are totally wrong about nanotechnology.

\section{Right now, they need to get really clear evidence.}

3. However, there are a great many unresolved issues related to nanotechnology.

4. If they don't, we are going to have big problems and the dangers could be horrendous.

5. If this does not occur, there are potential threats to public safety. safe.

6. They need to do more research till they're sure it's totally

7. At first, everyone got excited about the new things that they could do with it.

8. Initially, the novel uses of nanotechnology in medicine and industry led to unlimited production.

9. At the present time, the evidence should be made available to the public.

10. In the past, insufficient controls led to widespread fatalities caused by asbestos [17].

2) Match the words on the right to the academic synonyms on the left.

\section{ADJECTIVES}
1. fundamental
a) basic
2. adequate
b) fruitful
3. distinct
c) broad
4. initial
d) native
5. objective
e) relevant
6. indigenous
f) unbiased
7. wide
g) crucial 

8. rewarding
h) sufficient
9. appropriate
i) clear
10. essential
j) main
11. principal
k) preliminary of:

The syntactic section of the module involves the analysis

- the structure and types of sentences of a scientific text; conjunctions and function words, signaling the transition to the next paragraph or section of the article; the structure of a typical paragraph and peculiarities of punctuation. of:

Exercises for developing these skills assume acquisition

- paired conjunctions and function words;

- conjunctions, the choice of which depends on the type of logical connection between parts of complex and compound sentences;

- parts of a paragraph in a logical order;

- selection or creation of a sentence that expresses the main idea of the paragraph (topic sentence), or a final sentence that summarizes the information (closing sentence);

- analysis and simulation of models;

- arrangement of punctuation marks in the text, etc.

In the beginning, learners perform exercises at the sentence level that assume:

- making sentences according to a model,

- combining simple sentences into complex and compound,

- arrangement of members of the sentence in the appropriate order.

Further exercises focus on the structure of the paragraph, and agreement of sentences. The presence of supports and training exercises provide the opportunity to fill the gaps in knowledge and develop the skills of generating an academic text with greater efficiency.

For example:

3) Change the following 15 passive-voice verbs into active. Cut its length in half! Avoid "we" pronouns as much as possible.

A retrospective review of all breast cancer patients treated for local recurrence in our hospital was performed. Cases with other cancers present or unknown primary were excluded. The information was gathered from the patient database of the Department of XXX, Turku University Central Hospital (TUCH), consisting of 5859 breast cancer patients. All the patient records in the database were reviewed, and those patients with local recurrence of breast cancer were selected to be included in this study. A total of 506 patients were found. They had been treated between 2005 and 2009 for local recurrence in the excision scar or for in-transit metastasis.

Factors predicting outcome after local recurrence were analyzed. Patient records were analyzed for patient, tumor, and treatment characteristics. Details on tumor characteristics were obtained from pathology reports, and all pathology reports were re-examined by a specialist in pathology to obtain all information on the primary tumor. Surgical and radiological reports were analyzed for follow-up data on patterns and timing of local recurrence. Furthermore, possible development of lymph node or distant metastases was recorded. The ABCD staging system from 2003 was used for grouping patients according to their stage of the primary disease [18].

4) Identify the Parts of a Topic Sentence. Circle the topic and underline the controlling idea in each of the following sentences.

1. Driving on freeways requires skill and alertness.

2. Driving on freeways requires strong nerves.

3. Driving on freeways requires an aggressive attitude.

4. The Caribbean island of Trinidad attracts tourists because of the calypso music.

5. Spectacular beaches made Puerto-Rico a tourist paradise.

6. Moving away from home can be a stressful experience for young people.

7. Many religious rules arose from the health needs of ancient times.

8. A major problem for many students is the high cost of tuition and books.

9. Participating in class discussions is a problem for several different groups of students.

10. In my opinion, television commercials for cosmetics lie to women.

11. Owning an automobile is a necessity for me [18].

The final section of the module includes acquaintance of learners with peculiarities of editing, arrangement of bibliography, submission of articles to the journals (Postwriting): correction of draft and final versions of the article, logical arrangement of the text, punctuation, bibliography in accordance with the requirements of the journal, style of academic writing; stages of submitting an article to the journal.

Exercises of the four sections of the module are primarily receptive and receptive-productive, as the purpose of these exercises is to remove language difficulties that learners may encounter when writing a scientific text, as well as to activate meta-communication signals used to clarify the design of the main parts of the academic text and the intention of the 
researcher. This complex of communicative exercises is based on the following lingua-didactic provisions:

- preponderance of preparatory exercises over communicative exercises;

- increasing complexity in discourse-cognitive tasks (from the compilation of a structurally simple message, to superphrasal unity and completely arranged academic text);

- separation of tasks for exercises with logical and semantic supports and situational exercises;

- mastering the English-Russian terminological apparatus of the academic style for providing better understanding of the material and transition to the productive and efficient process of academic writing.

The tasks of the last section of the module aim at developing creative skills of writing an academic text in English and seem to be mostly productive in nature, paying particular attention to the content of the text, and not its linguistic form, as it correlates with the real conditions of scientific communication and a concrete result. At this stage, learners:

- improve the skills of step-by-step modeling of the functionally relevant scientific text in English due to correct verbal and paraverbal means;

- develop the skills of the most accurate transfer of scientific knowledge in the English language;

- get acquainted with the basic styles of citation, ways to prevent plagiarism and the technique of editing one's own article.

The largest scope of independent work of the learners falls to the last section of the module, the result of which is an academic text presenting the research conducted by the author.

The second module for non-linguists contains topics that duplicate those of the first module, but are presented in Russian, which allows learners with an insufficiently high level of competence in English to acquire the most significant aspects of academic discourse, to structure their scientific text logically, to substantiate the hypothesis, to use correctly paraverbal means and meta-communication signals, to prepare the draft version of the article in the AIMRAD format.

\section{CONCLUSION}

Thus, mastering academic writing competence within the program "Fundamentals of academic writing in English" promotes development of academic literacy and publishing activity of researchers, enabling them to present the results of an academic research in a condensed form at different stages of scientific activity.

The technique of mastering fundamentals of academic writing in English and the system of exercises of structural, compositional, lexical, grammatical and syntactic levels are presented in the manual "Maximize your publication chances in international journals" [19]. The manual considers the experience of foreign and domestic methodologists of language training in academic writing in English and possible ways of improvement its educational potential due to deployment of modern approaches and new techniques in international scientific communication.

\section{References}

[1] O.N. Krutikov, "Academic writing" in terms of "academic capitalism," Higher education in Russia, No. 5, pp. 43-47, 2012.

[2] E.V. Makarova, Teaching academic writing format imrad English, http://elib.bsu.by/handle/123456789/159363 - date of access 03.02.2017

[3] M.A. Fedorova, and A. M. Zavyalov, "The Development of a culture of scientific language in a technical University," Higher education in Russia, No.3, 2013, pp. 129-136.

[4] E.M. Bazanova, "Laboratory of scientific communication: the Russian experience," Higher education in Russia, No. 8-9, pp. 135-143, 2015.

[5] I. Bruce, Theory and Concepts of English for Academic Purposes. Palgrave Macmillan, 2011, 227p.

[6] I.B. Korotkina, Professional text: academic writing for school heads and education experts. Lambert Academic Publishing, GmbH \& Co.KG, 2011, 176p.

[7] O.M. Demidova, "The Development of academic writing skills masters in non-linguistic University," The Young scientist, No. 1, pp. 510-516, 2014.

[8] T. Morley-Warner, Academic Writing and Process. University of Technology, Sydney, 2000, 76p.

[9] Y.V. Rozanova, "The Role of academic writing in preparation of bachelors in a technical University," The Young scientist, No. 6, pp. 674-677, 2015.

[10] I.B. Korotkina, Academic writing: process, product and practice. Textbook for high schools. Moscow: Publishing House Yurayt, 2015, $295 \mathrm{p}$.

[11] K. Folse, J. Muchmore-Vokoun, and et al., Great Writing 2: Great Paragraphs. Boston: Houghton Mifflin, 2010, 320p.

[12] E.S. Ostrovskaya, and O.V. Vyshegorodtseva, "Academic writing: the concept and practice of academic writing in English," Higher education in Russia, No. 7, pp. 104-112, 2013.

[13] S.V. Bogolepova, "Teaching academic writing in English: approaches and products," Higher education in Russia, No. 1, pp. 87-94, 2016.

[14] Ho Mei-ching, "Navigating scholarly writing and international publishing: Individual agency of Taiwanese EAL doctoral students," Journal of English for Academic Purposes, vol. 27, May 2017, pp. 1-3, 2016.

[15] A. Gebrila, and L.Plakansb, "Source-based tasks in academic writing assessment: Lexical diversity, textual borrowing and proficiency," Journal of English for Academic Purposes, vol. 24, December 2016, pp.78-88, http://doi.org/10.1016/j.jeap.2016.10.001 - date of access 20.03.17.

[16] E. Steven, "The Elements of academic style: writing for the Humanities," in Journal of Scholarly Publishing, vol. 46, No. 4, July 2015, pp. 399-403, http://dx.doi.org/10.3138/jsp.46.4.BR2 - date of access 17.02.2017.

[17] L. Hamp-Lyons, and B.Heasley, Study writing: a course in written English for academic and professional purposes. Cambridge: CUP, 2006, 213p.

[18] N. Reid, Getting published in international journals: Writing strategies for European social scientists. Oslo: NOVA, 2010, 303p.

[19] T.N. Astafurova, I.V. Skrynnikova, and N.S. Kolyabina, Maximize your chances for publication in international journals: a training manual. Volgograd, 2017, 185p. 